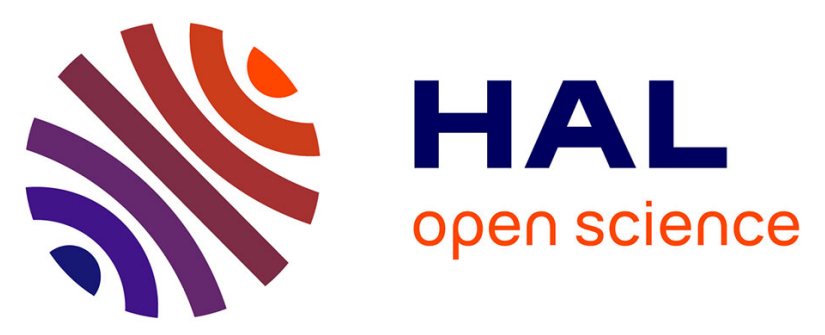

\title{
Temporal and spatial aspects concerning the realizations of the voicing contrast in German alveolar and postalveolar fricatives
}

\author{
Susanne Fuchs, Jana Brunner, Anke Busler
}

\section{- To cite this version:}

Susanne Fuchs, Jana Brunner, Anke Busler. Temporal and spatial aspects concerning the realizations of the voicing contrast in German alveolar and postalveolar fricatives. Advances in Speech Language Pathology, 2007, 9 (1), pp.90 - 100. 10.1080/14417040601094315 . hal-00371321

\section{HAL Id: hal-00371321 \\ https://hal.science/hal-00371321}

Submitted on 27 Mar 2009

HAL is a multi-disciplinary open access archive for the deposit and dissemination of scientific research documents, whether they are published or not. The documents may come from teaching and research institutions in France or abroad, or from public or private research centers.
L'archive ouverte pluridisciplinaire HAL, est destinée au dépôt et à la diffusion de documents scientifiques de niveau recherche, publiés ou non, émanant des établissements d'enseignement et de recherche français ou étrangers, des laboratoires publics ou privés. 
Temporal and spatial aspects concerning the realisations of the voicing contrast in German alveolar and postalveolar fricatives

SUSANNE FUCHS ${ }^{1}$, JANA BRUNNER ${ }^{1,2,3}$, ANKE BUSLER ${ }^{1}$

1. Zentrum für Allgemeine Sprachwissenschaft, Typologie und Universalienforschung (ZAS) Berlin, Germany

2. Humboldt-Universität zu Berlin, Germany

3. Institut de la Communication Parlée, INPG, CNRS \& Université Stendhal Grenoble, France

Correspondence: Susanne Fuchs, PhD, ZAS/Phonetik, Schützenstrasse 21, 10117 Berlin Germany. Tel. ++49 30 47530632. Fax. ++49 3020192 402. E-mail: fuchs@zas.gwzberlin.de

Running head: Voicing contrast in fricatives 


\begin{abstract}
This study investigates the phonetic realisations of voicing contrast in alveolar and postalveolar fricatives production in different word positions in order to understand the temporal and spatial production strategies used in the control of voicing and frication, and to provide a frame of reference for speech therapy despite the inter-speaker variation. Seven native speakers of German, originally coming from various regions, participated in the experiment. Acoustic signals were recorded onto DAT, and tongue palate contact patterns were recorded by means of electropalatography (EPG). The temporal parameters were measured using the acoustic signals and the spatial parameters were measured based on the EPG data. The corpus included real words with /s, z, $\int$, 3/ occurring at word initial, medial and final positions. Temporal results showed that differences in the overall frication duration for voicing contrast occur at almost all positions (with longer duration for voiceless phonemes). However, voicing during the frication interval was a less reliable discriminator, particularly for Southern German speakers and at word final position. We found a positive correlation between the relative voicing duration and the amount of tongue palate contact for subjects who produced voicing. Especially for the postalveolars, voicing also coincides with more front articulation. Results are discussed with respect to laryngeal-oral co-ordination and aerodynamics.
\end{abstract}

\title{
Key words
}

Voicing contrast, devoicing, sibilants production, spatio-temporal aspects, laryngeal-oral coordination 


\section{Introduction}

Alveolar and postalveolar fricatives, the sounds which will be studied here, present a particular challenge since firstly, they are difficult to acquire and susceptible to distortions, and secondly, the mechanisms underlying the production of the voicing contrast in fricatives, frication and voicing, are to some extent contradictory. Details of these mechanisms are rarely investigated and may therefore have led to divergent articulatory findings. The following sections provide a theoretical background for the facts mentioned above.

\subsection{Distortions of alveolar and postalveolar fricatives}

Alveolar and postalveolar fricatives are sounds which are very often distorted, especially by patients who suffer from sensori-motor coordination problems, hearing impairments, or anatomical abnormalities such as cleft palate (e.g., Boomer \& Laver, 1968; Dagenais \& Critz-Crosby, 1991; Fletcher, Dagenais, \& Critz-Crosby, 1991; Gibbon, 2004). Fletcher et al. (1991) described the treatment of profoundly hearing-impaired children using electropalatography (EPG) and they showed that learning /z/ was the most difficult task in comparison to stops (least difficult) or voiceless fricatives. They suggested that this finding could be due to the different physiological complexity of these sounds with /z/ being the most complex phoneme. This suggestion is in agreement with results reported by Fuchs, Perrier, Geng and Mooshammer (2006), who found evidence for two different motor control strategies for normal productions of alveolar stops (/t/) and fricatives (/z/). For alveolar stops, the tongue is not controlled via a fine positioning at the alveolar ridge, but the movement is planned towards a target above the alveolus, resulting in a collision of the tongue at this location (for the idea of this control strategy, see also Löfqvist \& Gracco, 1997). Hence, the palate is used as a spatial reference which automatically blocks the tongue’s movement. In terms of stability and simplicity, this control strategy seems to be extremely efficient in comparison to positioning precisely the lateral margins of the tongue at the palate, which is a 
more difficult control strategy (probably involving feedback information) used in the production of alveolar fricatives.

Conventional treatment of phonetic disorders consists of various steps. It starts with a verbal description of the articulation of the relevant sounds by the speech-language pathologist. It then continues with a process involving the perceptual discrimination between the distorted production and the target sound by the client, followed by a learning process of the appropriate pronunciation due to imitation of single versus larger speech units by the client. The additional use of visual feedback via EPG has been proven to be a successful tool in treating articulation disorders in different clinical populations, for instance, children with cleft palate (Gibbon, 2004; Michi, Yamashita, Suzuki, \& Yoshida, 1993), children with persisting speech difficulties without any known organic aetiology (Carter \& Edwards, 2004), or individuals with hearing-impairment (Fletcher et al., 1991). In particular, EPG speeds up the learning process of correct /s/ pronunciation in comparison to conventional speech therapy without any visual feedback (Michi et al., 1993).

One of the general difficulties for speech therapy consists of a clear definition of 'normal' and 'pathological' speech. Roberts, McLeod and Sita (2002) searched the EPG literature for normal and impaired /s/ and /z/ productions and divided the results for impaired alveolar fricatives into the following categories: higher overall amount of tongue-palate contacts, higher amount of contacts in the palatal region, lateral gaps or fewer tongue palatal contacts in comparison to the normal (for a case study on impaired /s/, see also Gibbon \& Hardcastle, 1987). Impaired alveolar fricative productions were manifold and sometimes contradictory, hence, no general pattern emerged. Slight asymmetries in the lateral contacts were no sign for impaired alveolar fricative productions and were frequently found in the normal patterns (see also Hamlet, Bunnell, \& Struntz, 1986, for EPG patterns produced by normal speakers). 
To summarise, alveolar and postalveolar fricatives are sounds which are frequently distorted by patients who have speech disorders due to different aetiologies. Distortions are probably caused by the more difficult speech production mechanisms of these sounds, in comparison to others such as alveolar stops. EPG is useful in speech therapy to improve the speed of the learning process of correct articulation. However, no unique pattern emerges when EPG data from normal and abnormal alveolar fricatives are compared.

\subsection{The voicing contrast in fricatives}

Although various studies have been carried out to investigate the voicing contrast in stops, detailed analyses of articulatory mechanisms involved in the voicing contrast of fricatives are rather rare, and often differ in their interpretation.

\subsubsection{Contradictory control strategies: Voicing and frication}

It is well known that voicing and frication demand different control strategies concerning the intraoral and subglottal pressure conditions in the vocal tract. Theoretically, voicing requires an adducted glottis and a transglottal pressure difference, with the pressure below the glottis (hereafter subglottal pressure) higher than the pressure in the oral cavity (hereafter intraoral pressure). This transglottal pressure difference is observed in an open vocal tract configuration, such as occurs during open vowel production. However, during the production of obstruents, the intraoral pressure rises before full articulatory closure or constriction is reached (Müller \& Brown, 1980). The intraoral pressure may rise to such an extent that the transglottal pressure difference necessary for voicing cannot be maintained, thus, the phonologically voiced obstruents become devoiced or partly devoiced. This is true unless other mechanisms such as cavity enlargement are realised, which aim to maintain the transglottal pressure difference (for an overview on cavity enlargement strategies in stop production, see Fuchs, 2005). Cavity enlargement has primarily been discussed with respect to stops production. Experimental evidence for its involvement in fricatives production has not been reported (except Narayanan, Alwan, \& Haker, 1995). It is possible to employ the 
strategy of cavity enlargement to maintain voicing during the production of obstruents by shifting the place of closure or constriction further to the front.

The production of frication requires an abducted glottis, a significant pressure drop across the oral constriction, and a high amount of airflow. An abducted glottis leads to a high amount of airflow. The pressure drop is created with a higher intraoral than atmospheric pressure by means of a small constriction and a larger cross-sectional area of the glottal constriction than the supraglottal constriction (Stevens, 1971). Airflow usually becomes turbulent when leaving the narrow channel and/or hitting an obstacle in the vicinity of the air stream. The teeth are the obstacle during the production of alveolar and postalveolar fricatives (Shadle, 1990; 1991).

When producing voiced fricatives, a very precise laryngeal-oral adjustment is assumed in order to balance the two contradictory mechanisms: a higher intraoral than atmospheric pressure for frication and a lower intraoral than subglottal pressure for voicing. Mawass (1997) studied the area of the supraglottal and glottal constriction for a given subglottal pressure by means of a model. He discussed about the region where both voicing and frication can be realised and this region is indeed very narrow. If the pressure balance between frication and voicing is not achieved, voicing is more likely to disappear than frication, resulting in devoicing of phonologically voiced fricatives rather than the loss of frication (Smith, 1997). The phonological terms, voiced and voiceless, are misleading to some extent, since phonologically voiced fricatives can be partially or totally devoiced. Hence, we will hereafter separate especially between 'phonologically voiced' and its actual realisation.

\subsubsection{Inconsistent results from the literature}

EPG studies which have investigated voicing contrast in normal speech production showed contrasting findings. On one hand, there are studies reporting no significant differences in EPG patterns between /s/ and /z/ or / / / and /3/ (e.g., Fletcher, 1989; Tabain, 2001), which suggest that voicing contrast in fricatives is only made at the laryngeal level, 
rather than the supralaryngeal level. On the other hand, the latest EPG studies on /s/ and /z/ production in English (McLeod, Roberts, \& Sita, 2006) and Hindi (Dixit \& Hoffman, 2004) showed a greater percentage of anterior tongue palate contact patterns and a smaller groove width for the voiced segments. Dixit and Hoffman (2004) suggested that the greater amount of EPG contact during the production of phonologically voiced fricatives could be a consequence of laryngeal action. During /s/ realisation, the glottis is open which guarantees the high amount of airflow necessary for the production of frication. In contrast, the glottis is adducted or slightly abducted when producing /z/. This impedes the airflow and the rise of intraoral pressure, causing insufficient intraoral pressure to produce frication. In such circumstances, a narrower groove resulting in more tongue palate contact would be a strategy to guarantee the pressure drop across the oral constriction, and thereby supports the creation of turbulent noise.

The controversial results reported in previous EPG studies could be due to the fact that phonologically voiced fricatives are often realised as partially devoiced or voiceless (Smith, 1997), and therefore the results become more similar to those of the phonologically voiceless phonemes. On the other hand, there are also certain environments or prosodic conditions in which phonologically voiced fricatives are realised as voiced and differ from voiceless. Hence, taking into account the actual realisation of voicing during frication in phonologically voiced and voiceless phonemes and their EPG data should enhance the understanding of the voicing contrast and its control strategies.

The aims of this study are, firstly, to investigate the realisations of voicing contrast in alveolar and postalveolar fricatives with respect to different word positions, and secondly, to understand the possible control strategies used for the simultaneous production of voicing and frication, two contradictory mechanisms with respect to aerodynamic requirements. The third aim is to provide a frame of reference for normal speech production. To achieve these, 
temporal parameters were calculated by means of the analysis of acoustic signals, and spatial parameters were calculated using EPG.

\section{Method}

German was chosen because, to our knowledge, there is a gap in the knowledge on voicing contrast in alveolar and postalveolar fricatives (Jessen, 1998), and additionally, German is known for the devoicing of phonologically voiced tokens in word initial and word final positions.

\subsection{Stimuli}

The German sound inventory consists of the following fricatives: /f, v, s, z, $\int, 3$, ç, x, в, $\chi, \mathrm{h} /$. The present study focuses on the alveolar and postalveolar fricatives /s, z, $\int, 3$ / and their peculiarities since the other fricatives are either subject to inventory restrictions with respect to vowel environment or they do not have a phonemic counterpart. The labiodentals are not included because their place of constriction cannot be captured by means of EPG.

Concerning alveolar fricatives, a few minimal pairs can be found in intervocalic word medial position. Mangold (1978) counted 56 minimal pairs in the German lexicon including words with inflection, but he found only 11 real word pairs, for instance: Muse "muse" [ ${ }^{1}$ mu:zə] vs. Muße "leisure” [ ${ }^{1}$ mu:sə]. All other pairs also involve a difference regarding the preceding vowel context. Phonologically voiced alveolar fricatives tend to coincide with preceding tense vowels or diphthongs and phonologically voiceless fricatives with lax vowels, for example, Risse “rifts” [ ${ }^{1}$ БISə] vs. Riese "giant” [ ${ }^{1}$ вi:zə]. In addition, Mangold found twice as many words with /i:z/ than with /iss/.

Only phonologically voiced alveolar fricatives exist at word initial position, except in the non-native vocabularies originated from English, Latin, Greek, and French (Mangold, 1978). This restricted inventory is surprising since word initial stressed positions are prosodically strong positions and should coincide with longer segment durations and more 
extreme articulatory patterns than weak positions (Keating, Cho, Fougeron, \& Hsu, 2004). These temporal and spatial parameters are however known to facilitate devoicing. That is, voiceless phonemes are often longer than voiced ones, and extreme articulatory patterns such as increased tongue palate contact rather speak for a smaller oral constriction and therefore devoicing. It is unclear why only phonologically voiced alveolars exist in such a strong position. The latest work based on the PhonDat2 database, a corpus of hand-labelled utterances of 16 speakers of different origins in Germany (Heid, 1998), provided quantitative results for regional variations with respect to devoicing of initial /z/. Southern German speakers mostly devoice initial /z/ in contrast to Northern German speakers.

Contrary to the alveolar fricatives, only voiceless fricatives exist in initial position for postalveolars, except the non-native vocabulary, for example, Genie “genius” [3 3 Ÿni:]. To round off the picture, the phonological rule of final devoicing applies at word final position (for an overview, see Brockhaus, 1995). The phonological rule is motivated by neutralisation of the voicing contrast in word-, morpheme- or syllable-final position, that is, phonologically voiced obstruents become voiceless.

To investigate the voicing contrast in German sibilants, a corpus following the German peculiarities in the different word positions was assembled. Some non-native vocabularies were included, particularly in those cases where a phonemic counterpart is missing in the German lexicon. Table 1 displays the selected target words. It should be noted that word pairs like Nase versus nasse also involve a tense-lax difference in the preceding stressed vowel, a fact which could have influenced the amount of tongue palate contact during the fricative production, since tense vowels are known to show more peripheral articulation than lax vowels in stressed position. However, the German /a/ is an exception, where there are only quantitative (temporal), but no qualitative differences, at least for Northern German speakers (Kohler, 1995). 
All target words were embedded in the carrier phrase, Sage _ bitte "Say _ please" and they were repeated ten times in randomised order. This resulted in approximately 190 tokens for each subject (1326 tokens for all speakers, four tokens were missing). The full set of speech materials also includes words where stops are located at different word positions and this will be investigated in future work.

\subsection{Speakers}

In order to investigate temporal and spatial characteristics of alveolar and postalveolar fricatives production in German, the speech of seven native speakers, four male speakers (BM, DM, JM, RM) and three female speakers (CF, JF, SF), were recorded by means of electropalatography (Reading system, EPG3). Speech signals were simultaneously recorded on a Digital Audio Tape (DAT). Sampling frequencies were $48 \mathrm{kHz}$ for the acoustic data and $100 \mathrm{~Hz}$ for EPG. All of the participants in this study are colleagues from the phonetics laboratory at the Centre for General Linguistics (ZAS) in Berlin, who have no known history of speech, language or hearing impairment, except for subject BM, who has a velopharyngeal dysfunction and a left-sided hearing impairment (both due to a traumatic accident). However, his daily speech does not sound impaired as judged by the colleagues in the lab and by his former students. Additionally, he was frequently a subject in electromagnetic articulography recordings, and his tongue movements did not show any peculiarities in comparison to other subjects.

Although all the speakers have lived in Berlin for at least 8 years, they grew up in different regions of Germany: JM and RM stem from the Mecklenburg area, the Northern part of former East Germany (close to Rostock); BM and CF are from Munich (Bavaria) in Southern Germany; SF grew up in the South of East Germany (Saxonia, close to the Czech border); DM is originally from Berlin and JF lived in Berlin most of her life.

\subsection{Measurements and procedures}




\subsubsection{Temporal measures and procedures}

For the acoustic analysis, the following time points were labelled using Praat (version 4.4.04) (Boersma \& Weenink, 2006):

- $\quad$ Frication onset (fric_on): the beginning of high frequency noise in the spectrogram;

- Voicing offset (voic_off): the voicing offset during the frication interval (the pitch tracker in Praat was used as a reference, with manual correction in case of faulty automatic calculations);

- $\quad$ Frication offset (fric_off): the end of high frequency noise in the spectrogram;

- $\quad$ F2 onset (f2_on): the beginning of the second formant (formants may be found throughout the whole frication segment in voiced intervocalic fricatives. In such cases, the increase in intensity and the increase in the acoustic envelope were taken into account as well); and

- $\quad$ F2 offset (f2_off): the end of the second formant (only the stressed vowels were considered).

Based on these landmarks, the following segment durations were calculated:

Frication duration: fricdur $=$ fric_off - fric_on

Voicing duration: voicdur = voic_off - fric_on

Relative voicing duration: voicdur_rel = voicdur $* 100 /$ fric_dur

Vowel duration of the stressed vowel: voweldur $=\mathrm{f} 2 \_$off $-\mathrm{f} 2 \_$on.

\subsubsection{EPG measurements and procedures}

The EPG data were imported into Matlab. The following parameters were measured within the acoustically defined frication interval:

- $\quad$ Percent of contact (PC): percent of contact over the whole palate

- $\quad$ Percent of anterior contact (ANT): percent of contact in the first 4 rows 
- $\quad$ Centre of gravity (COG) index: weighted index in the front-back dimension, with higher values corresponding to more anterior articulation (Hardcastle, Gibbon, \& Nicolaidis, 1991).

The ANT is a reasonable measure to account for the voicing contrast in alveolar fricatives. However, it is not a reliable measure for the description of the postalveolar contrast, since some of the speakers in the present study realised the oral constriction of these sounds in a more posterior position than the ANT can capture. Hence, PC was chosen for the analysis of the postalveolars. The COG index was included as well since forward versus backward movement is another strategy to manipulate the aerodynamic conditions in the oral cavity.

Within a given frication interval, we averaged the corresponding ANT or PC or COG values in each repetition. The relative frequency of contact was calculated for the ten repetitions at the first time point in the frication interval where the ANT (for alveolars) or PC (for postalveolars) reached its maximum constriction. This time point was assumed to be the articulatory target.

SPSS 11.5 software package (Jannsen \& Laatz, 2005) was used for statistical analysis.

\section{Results}

\subsection{Temporal results: Voicing and frication duration}

Figure 1 shows the averaged temporal results split by phoneme, word position, and speaker. The complete bars correspond to the frication interval of the relevant phoneme ordered by word position. The voiced interval is marked in grey and the voiceless interval is displayed in black.

Insert figure 1 around here

One of the major differences between phonologically voiced and voiceless phonemes is the overall duration of the frication interval, with longer durations for the voiceless even at 
the neutralisation position (word final, except for SF). However, if the differences in voicing duration are as pronounced as in $/ \mathrm{S} /$ and $/ 3 /$ at word medial position for RM, SF, and JM, the overall frication duration can be similar for the contrast pair. Additionally, figure 1 clearly displays two results: first, the actual realisation of voicing in the frication interval depends on word position and second, it depends on the speaker. The most likely position where a 'true' voicing contrast is produced is the word medial position. The position where voicing disappears quickly or where it is not realised is the word final position. Results for the word initial position varied according to the speaker. BM, CF and SF do not produce any obvious differences in voicing duration between the phonologically voiced and voiceless fricatives. These three speakers originally stem from Southern parts of Germany. For the two Bavarians, $\mathrm{BM}$ and $\mathrm{CF}$, it is even the case that the phonological voicing contrast is never realised on the basis of differences in voicing duration. For SF, differences in voicing duration are still observed in the word medial position. The other subjects, who originally stem from the Northern parts of Germany, show a considerably longer voicing duration for phonologically voiced phonemes at word initial and medial positions than for the voiceless cognates. However, the size of the samples in the present study is too small to test the difference between speakers with respect to their regional origin and further work is necessary to provide data on regional and dialectal variations.

\subsection{Results for spatial parameters: ANT, PC and COG}

Figures 2 and 4 show the results for the spatial parameters of the voicing contrast measured with EPG. For visualisation purposes, the COG index and its standard deviation for each of the speakers was multiplied by 9. Figure 2 displays the results of ANT and COG index for the alveolars, and figure 4 shows the results of PC and COG index for the postalveolars.

Insert Figure 2 around here 
In general, for the alveolars, the differences in ANT are most pronounced at word initial position (BP, DM, JF, JM, RM, SF with $\mathrm{p}<0.004$ for all subjects), followed by word medial position ( $\mathrm{p}<0.018$ for DM and JF; $\mathrm{p}>0.001$ for JM, RM, and SF). At word final position, the differences are not significant in six out of seven speakers (except JM).

Generally, if differences between phonologically voiced and voiceless alveolars occur, then more EPG contacts are on average realised in phonologically voiced alveolar fricatives than in their voiceless counterparts. The differences are very subtle and often correspond to one or two electrodes. However, as mentioned in the introduction, the glottal constriction area has to be larger than the oral constriction to create a pressure drop across the oral constriction (Stevens, 1971). This holds true for voiceless fricatives, where the glottis is open. Indeed, a very narrow oral constriction was found for these sounds. In phonologically voiced phonemes, an even smaller constriction width was produced which was verified on the basis of the EPG frequency plot. An example is provided in figure 3, for subject DP. The area where none of the EPG electrodes ever had contact is surrounded by a black line. In this particular case, a clear difference between the size of the constriction channels can be seen, with a smaller constriction width for /z/ than for /s/. Frequency of contact was also taken into account.

Insert Figure 3 around here

Differences in constriction size may also be tiny, since the actual distance between the electrode's placement in the artificial palate (Reading system) is on average $2.89 \mathrm{~mm}$ in the first two anterior rows and $3.13 \mathrm{~mm}$ in the third and fourth row (in Fuchs, Brunner, \& Busler, in preparation; data are based on 20 EPG palates including the subjects of this study). Descriptions of the constriction width in alveolar fricative production varies from 6-12 mm 
(Ladefoged \& Maddieson, 1996). Differences in the constriction width of one or two electrodes are therefore large in terms of the creation of a pressure drop.

The results of the COG differences in alveolars appear similar to those of the ANT differences, but are less pronounced. The voicing contrast in the production of postalveolars as shown in figure 4 involves significant differences in front versus back articulation, that is, phonologically voiced tokens are realised further to the front than their voiceless counterparts ( $\mathrm{p}<0.001$ for DM, JF, JM, and RM at medial position; JM and DM at word final position).

Insert Figure 4 around here

The results also show greater PC values in the phonologically voiced phonemes than the voiceless ones, but the differences are smaller. A contrasting result, with more contacts for the voiceless phonemes, was found in CF and SF.

\subsection{Relation between temporal and spatial aspects}

As mentioned earlier, previous findings (e.g., Dixit \& Hoffman, 2004; Fletcher, 1989; McLeod et al., 2006; Tabain, 2001) differed with respect to whether they found a supralaryngeal involvement in terms of tongue palate contact in the voicing contrast of fricatives or not. None of these studies considered the actual phonetic realisations of the phonologically voiced phonemes. They can become devoiced and thereby similar to the voiceless. To take this factor into account, the correlations between the following parameter were evaluated: ANT and relative voicing duration; COG index and the relative voicing duration for the alveolar fricatives; PC and relative voicing duration; COG index and relative voicing duration for the postalveolars. All phonologically voiced and voiceless fricatives either alveolar or postalveolar were pooled together in order to base the analysis on the phonetic realisation, instead of the phonological terms. Note that, first, the Spearman Rho correlation, which does not assume normally distributed variables, was used. The relative 
voicing duration was bimodally distributed for all subjects except BM and CF. The bimodal distribution was not a result of pooling phonologically voiced and voiceless together. It was due to the fact that a large number of data were fully voiced and the rest were only partially voiced. Second, since word position (prosody) may also affects the segment's duration, the relative voicing duration, which is a normalised voicing duration, was used for calculating the correlations. Table 2 depicts the results split by speaker.

Insert table 2 around here

In general, for all the subjects who produced voicing, significant positive correlations were found, that is, longer relative voicing duration coincides with a greater percentage of either ANT for the alveolars (except BM, CF) or PC for the postalveolars (except BM, CF, DM). Correlation coefficients may be weak in some cases since the differences in tongue palate contact, although significant, are very subtle and correspond quite often to contact differences of one to three electrodes. However, in terms of oral constriction, such difference may have a major effect on the width of the air channel and therefore on the production of turbulent noise.

Interestingly, for DM and RM, the relative voicing duration correlates to a somewhat greater extent with the COG for the alveolars. In the postalveolars, DM showed an insignificant correlation between the relative voicing duration and the PC, whereas there was a significant correlation between the COG index and relative voicing duration. Since in these cases a more frontal articulation corresponds to longer relative voicing, this result may rather speak for a strategy to enlarge the oral cavity and decrease intraoral pressure in order to facilitate voicing than for a mechanism to increase intraoral air pressure and the amount of airflow. 
The data were splitted with respect to word position and the correlations between these parameters were evaluated again: at word initial position, all speakers showed a positive significant correlations ranging from 0.324 to 0.723 for the alveolars (except SF who showed insignificant correlation, and CF with negative correlations). At word medial position, the correlations are less pronounced and occur only for JM, RM, and SF (PC-voicdur_rel) and JF, JM, RM, and SF (COG-voicdur_rel). This effect may be explained in terms of the tense-lax differences in the preceding vowel which often coincide with differences in the phonological voicing status. No significant correlation was found for the word final position (position for neutralisation).

For the postalveolars, we could only consider the word medial and final positions. The word medial position is clearly the one where a strong positive relation between temporal and spatial parameters exist, except for BM, CF, SF for the COG, and RW for the PC. For all other speakers, significant correlation coefficients between 0.532 and 0.845 were found. All subjects showed greater correlations between COG and voicdur_rel than PC and voicdur_rel. Voicing coincides with a more frontal articulation and more tongue palate contact patterns for the postalveolars. The strength of the effect in the postalveolars can be explained by the fact that these sounds are not limited in their degree of freedom, whereas tongue movement in the alveolar production is limited due to the teeth. Additionally, the more posterior the overall constriction, the higher the intraoral pressure and the more likely the devoicing of phonologically voiced tokens (Ohala, 1983). Placing the tongue further to the front may be a necessary strategy to maintain the transglottal pressure difference and thus, voicing. At word final position (position for final devoicing), six out of seven subjects show no significant correlation, only DM showed a strong correlation between COG and voicdur_rel.

\section{Summary and conclusion}

By means of acoustics and electropalatography, the present study investigated the temporal and spatial characteristics of voicing contrast in fricative production at three 
different word positions. Seven native speakers coming originally from different regions in Germany were recorded. This study could be seen as a step towards the understanding of possible control strategies for the realisation of both voicing and frication, two rather contradictory mechanisms with respect to aerodynamic requirements. This study also provides a frame of reference for speech therapy, since alveolar fricatives are frequently distorted in particular.

The results of the temporal parameters revealed that, for voicing contrast, the differences in overall frication duration were generally more stable than the differences in voicing duration, since Southern German speakers realise all phonologically voiced tokens in the main part of the frication interval as voiceless, but the voiced phonemes are still shorter in overall duration in comparison to the voiceless ones. Difference in frication duration were also found for the word final position (position for neutralisation), but the extent of difference was smaller and it was not observed in every subject. Considering spatial aspects, one of the major outcomes of this study is the higher amount of anterior contact in phonologically voiced than in voiceless alveolars. These results are only found in those speakers who realise voicing but not for those who devoice. The greater amount of contact is attributed to a narrower medial groove. For postalveolars, similar but less pronounced differences have been shown for the PC. An additional and even stronger characteristic was that speakers who realise a true voicing contrast place their tongue further to the front (anterior) in the voiced postalveolars than in the voiceless. This mechanism has been interpreted with respect to the maintenance of voicing.

We conclude that the voicing contrast involves an appropriate laryngeal-oral coordination and is not only realised due to differences at the laryngeal level. The present EPG results are in agreement with McLeod et al. (2006) and Dixit and Hoffman (2004). In addition, for the alveolars we found evidence that the relative voicing duration and the percent of anterior contacts correlate, that is the longer relative voicing duration, the more anterior 
contacts are produced. We conclude that for alveolars, building a narrower channel where air is passing through is an appropriate strategy to create a pressure drop, increase the airflow, and thereby to realise turbulent noise even when the glottis is only slightly open or closed (Dixit \& Hoffman, 2004). The realisation of such a small constriction channel should be particularly sensitive to distortions and may also be one of the reasons why patients have the most difficulty in producing these sounds (Fletcher et al., 1991), or why in general children acquire these sounds later in comparison to stops. For postalveolars, a more frontal articulation for the realisation of voicing versus an articulation further to the back for voiceless can be introduced in speech therapy.

\section{Acknowledgements}

This work was supported by a grant from the German Research Council (DFG) GWZ 4/8-1, P.1. We would like to thank our subjects, Jörg Dreyer for technical expertise, the editors of this special issue, two anonymous reviewers, Christine Mooshammer, Pascal Perrier, Pauline Welby, Phil Hoole, Bernd Pompino-Marschall, Martine Toda for comments on an earlier version of this paper, and John Tammena for proof-reading. This work is dedicated to Dieter Fuchs.

\section{Footnotes}

1. Based on a questionnaire (2004), $84 \%$ of the 4564 German participants pronounced the word cent with initial [s], 9.8\% with [ts], and 6.2\% used both forms (see http://www.sprechwiss.uni-halle.de/aktuelles/index.html). Since in the majority of cases the fricative instead of the affricate was chosen, we included the word in our corpus. 


\section{References}

Boersma, P., \& Weenink, D. (2006). Praat: Doing phonetics by computer (Version 4.4.04) [Computer program]. Retrieved from http://www.fon.hum.uva.nl/praat/

Boomer, D. S., \& Laver, J. D. M. (1968). Slips of the tongue. British Journal of Disorders and Communication, 3(1), 1-12.

Brockhaus, W. (1995). Final devoicing in the phonology of German. Linguistische Arbeiten 337. Tübingen: Niemeyer.

Carter, P., \& Edwards, S. (2004). EPG therapy for children with longstanding speech disorders: Predictions and outcomes. Clinical Linguistics \& Phonetics, 18(6-8), 359-372.

Dagenais, P. A., \& Critz-Crosby, P. (1991). Consonant lingual-palatal contacts produced by normal-hearing and hearing-impaired children. Journal of Speech and Hearing Research 34, 1423-1435.

Dixit, R. P., \& Hoffman, P. R. (2004). Articulatory characteristics of fricatives and affricates in Hindi: An electropalatographic study. Journal of the International Phonetic Association, 34(2), 141-159.

Fletcher, S. G. (1989). Palatometric specification of stop, affricate, and sibilant sounds. Journal of Speech and Hearing Research, 32, 736-748.

Fletcher, S. G., Dagenais, P. A., \& Critz-Crosby, P. (1991). Teaching consonants to profoundly hearing-impaired speakers using palatometry. Journal of Speech and Hearing Research, 34, 929-942.

Fuchs, S. (2005). Articulatory correlates of the voicing contrast in alveolar obstruent production in German (Doctoral dissertation, Queen Margaret University College, 2005). ZAS Papers in Linguistics, 41.

Fuchs, S., Brunner, J., \& Busler, A. [Do inter-speaker differences in palate morphology shape individual's /s/ and /S/ realization? Evidence from English and German]. Unpublished manuscript. 
Fuchs, S., Perrier, P., Geng, C., \& Mooshammer, C. (2006). What role does the palate play in speech motor control? Insights from tongue kinematics for German alveolar obstruents. In J. Harrington \& M. Tabain (Eds.), Speech production: Models, phonetic processes and techniques (pp. 149-164). New York: Psychology Press.

Gibbon, F. E. (2004). Abnormal patterns of tongue-palate contact in the speech of individuals with cleft palate. Clinical Linguistics \& Phonetics, 18(4-5), 285-311.

Gibbon, F., \& Hardcastle, W. (1987). Articulatory description and treatment of "lateral /s/" using electropalatography: A case study. Journal of Disorders of Communication, 22, 203-217.

Hamlet, S. L., Bunnell, H.T., \& Struntz, B. (1986). Articulatory asymmetries [Letter to the Editor]. Journal of the Acoustical Society of America, 79(4), 1164-1169.

Hardcastle, W. J., Gibbon, F., \& Nicolaidis, K. (1991). EPG data reduction methods and their implications for studies of lingual coarticulation. Journal of Phonetics, 19, 251-266.

Heid, S. (1998). Phonetische variation: Untersuchungen anhand des PhonDat2-Korpus [Phonetic variation - examinations based on the PhonDat2 corpus]. Forschungsberichte des Instituts für Phonetik und Sprachliche Kommunikation der Universität München (FIPKM), 36, 193-368.

Jannsen, D., \& Laatz, W. (2005). Statistische Datenanalyse mit SPSS für Windows (5th ed.). Berlin: Springer Verlag.

Jessen, M. (1998). Phonetics and phonology of tense and lax obstruents in German. Amsterdam \& Philadelphia: John Benjamins.

Keating, P., Cho, T., Fougeron, C., \& Hsu, C.-S. (2004). Domain initial articulatory strengthening in four languages. In J. K. Local, R. Ogden \& R. A. M. Temple (Eds.), Papers in Laboratory Phonology VI: Phonetic interpretation (pp. 145-163). Cambridge: Cambridge University of Press. 
Kohler, K. J. (1995). Einführung in die Phonetik des Deutschen. Berlin: Erich Schmidt Verlag.

Ladefoged, P., \& Maddieson, I. (1996). The sounds of the world's languages. Oxford: Blackwell Publishers.

Löfqvist, A., \& Gracco, V. L. (1997). Lip and jaw kinematics in bilabial stop consonant production. Journal of Speech, Language, and Hearing Research, 40(4), 877-893.

Mangold, M. (1978). Zur Frage der Opposition /s/: /z/ im Deutschen. Frankfurter Phonetische Beiträge II = Forum Phoneticum, 16, 23-41.

Mawass, K. (1997). Synthèse articulatoire des consonnes fricatives du français. Unpublished $\mathrm{PhD}$ thesis at Institut National Polytechnique Grenoble.

McLeod, S., Roberts, A., \& Sita, J. (2006). Tongue/palate contact for the production of /s/ and /z/. Clinical Linguistics \& Phonetics, 20(1), 51-66.

Michi, K. Yamashita, Y., Suzuki, N., \& Yoshida, H. (1993). Role of visual feedback treatment for defective /s/ sounds in patients with cleft palate. Journal of Speech and Hearing Research, 36, 277-285.

Müller, E. M., \& Brown Jr., W. S. (1980). Variations in the supraglottal air pressure waveform and their articulatory interpretation. Speech and Language: Advances in Basic Research and Practice, 4, 317-389.

Narayanan, S. S., Alwan, A. A., \& Haker, K. (1995). An articulatory study of fricative consonants using magnetic resonance imaging. Journal of the Acoustical Society of America, 98(3), 1325-1347.

Ohala, J. J. (1983). The origin of sound patterns in vocal tract constraints. In P. F. MacNeilage (Ed.), The production of speech (pp. 189-216). New York: Springer Verlag. Roberts, A., McLeod, S., \& Sita, J. (2002). Describing normal and impaired /s/ and /z/ using EPG. ACQuiring Knowledge in Speech, Language and Hearing, 4, 158-163. 
Shadle, C. H. (1990). Articulatory-acoustic relationships in fricative consonants. In W. J. Hardcastle \& A. Marchal (Eds.). Speech production and speech modelling (pp. 187209). Dordrecht: Kluwer Academic Press.

Shadle, C. H. (1991). The effect of geometry on source mechanisms of fricative consonants. Journal of Phonetics, 19, 409-424.

Smith, C. L. (1997). The devoicing of /z/ in American English: Effects of local and prosodic context. Journal of Phonetics, 25, 471-500.

Stevens, K. N. (1971). Airflow and turbulence noise for fricative and stop consonants: Static considerations. Journal of the Acoustical Society of America, 50(4), 1180-1192.

Tabain, M. (2001). Variability in fricative production and spectra: Implications for the hyperand hypo- and quantal theories of speech production. Language and Speech, 44(1), 5794. 


\section{Appendix}

Table 1. Real word corpus with voiced and voiceless sibilants in the three different word positions (left to right columns); words in bold = graphematic representations, below in parentheses: English translation and information if the word does not belong to German native vocabulary; phonetic transcription in squared brackets.

\begin{tabular}{|c|c|c|c|}
\hline & Word initial & Word medial & Word final \\
\hline$/ \mathrm{s} /$ & $\begin{array}{l}\text { Cent } \\
\left.\text { (cent, non-native) }{ }^{1} \mathrm{~s} \varepsilon n t\right] \\
\text { Sex } \\
\text { (sex, non-native) }\left[{ }^{1} \mathrm{~s} \varepsilon \mathrm{ks}\right]\end{array}$ & $\begin{array}{l}\text { Nasse } \\
\text { (wet, fem.) [ }{ }^{1} \text { nasə] } \\
\text { Muße } \\
\text { (leisure) [ }{ }^{1} \text { mu:sə] } \\
\text { Weiße } \\
\text { (white) [1 }{ }^{1} \text { væ:sə] }\end{array}$ & $\begin{array}{l}\text { Laß! } \\
\text { (let!) [1las] }\end{array}$ \\
\hline$/ \mathbf{z} /$ & $\begin{array}{l}\text { Salat } \\
\text { (salad) [za'la:t] } \\
\text { Sahne } \\
\text { (cream) [ }{ }^{1} \text { za:nə] } \\
\text { Sehne } \\
\text { (tendon) [1 ze:nə] } \\
\text { Sechs } \\
\text { (six) [ }{ }^{1} \text { zeks] }\end{array}$ & $\begin{array}{l}\text { Nase } \\
\text { (nose) [ }{ }^{1} \text { na:zə] } \\
\text { Muse } \\
\text { (muse) [1'mu:zə] } \\
\text { Weise } \\
\text { (wise) [ }{ }^{1} \text { væ:zə] }\end{array}$ & $\begin{array}{l}\text { Las } \\
\text { (past tense from read) } \\
{\left[{ }^{1} \text { la:s] }\right.}\end{array}$ \\
\hline$/ 2 /$ & $\begin{array}{l}\text { Schabe } \\
\left.\text { (cockroach)[1 } \int a: b ə\right]\end{array}$ & $\begin{array}{l}\text { Tasche } \\
\text { (bag) }\left[{ }^{1} \mathrm{t}^{\mathrm{h}} \mathrm{a} \int \mathrm{]}\right]\end{array}$ & $\begin{array}{l}\text { Lasch } \\
\text { (lackadaisical) [1a)] }\end{array}$ \\
\hline$/ 3 /$ & - & $\begin{array}{l}\text { Gage } \\
\text { (salary, non-native) } \\
\text { ['ga:3ə] }\end{array}$ & $\begin{array}{l}\text { Courage } \\
\text { (spunk, non-native) } \\
{\left[\mathrm{ku}^{1} \text { ธa }\right]}\end{array}$ \\
\hline
\end{tabular}


Table 2

Correlation coefficients after Spearman-Rho, significant correlations are printed in bold.

\begin{tabular}{|c|c|c|c|c|c|c|}
\hline $\begin{array}{l}\text { Correlation } \\
\text { Coefficients }\end{array}$ & \multicolumn{3}{|c|}{$\begin{array}{c}\text { /s/ \&/z/ } \\
\text { ANT \& voicdur_rel } \\
\text { COG \& voicdur_rel }\end{array}$} & \multicolumn{3}{|c|}{$\begin{array}{c}/ \int / \& / 3 / \\
\text { PC \& voicdur_rel } \\
\text { COG \& voicdur_rel }\end{array}$} \\
\hline Speaker & $\mathrm{n}$ & $\mathrm{R}$ & P-value & $\mathrm{n}$ & $\mathrm{R}$ & P-value \\
\hline $\mathrm{BM}$ & 140 & $\begin{array}{l}-0.149 \\
-0.113 \\
\end{array}$ & $\begin{array}{l}0.078 \\
0.183\end{array}$ & 49 & $\begin{array}{r}-0.120 \\
0.203\end{array}$ & $\begin{array}{l}0.413 \\
0.162\end{array}$ \\
\hline $\mathrm{CF}$ & 140 & $\begin{array}{l}-0.119 \\
-0.119 \\
\end{array}$ & $\begin{array}{l}0.162 \\
0.160 \\
\end{array}$ & 50 & $\begin{array}{r}-0.052 \\
0.081 \\
\end{array}$ & $\begin{array}{l}0.721 \\
0.577 \\
\end{array}$ \\
\hline $\mathrm{DM}$ & 137 & $\begin{array}{l}0.324 \\
0.484 \\
\end{array}$ & $\begin{array}{l}>0.001 \\
>0.001\end{array}$ & 50 & $\begin{array}{l}0.225 \\
\mathbf{0 . 5 2 6} \\
\end{array}$ & $\begin{array}{r}0.115 \\
>0.001 \\
\end{array}$ \\
\hline JF & 139 & $\begin{array}{l}0.415 \\
0.341\end{array}$ & $\begin{array}{l}>0.001 \\
>0.001\end{array}$ & 50 & $\begin{array}{l}0.446 \\
0.357\end{array}$ & $\begin{array}{l}0.001 \\
0.011 \\
\end{array}$ \\
\hline JM & 139 & $\begin{array}{l}0.655 \\
0.567\end{array}$ & $\begin{array}{l}>0.001 \\
>0.001\end{array}$ & 50 & $\begin{array}{l}0.474 \\
0.566\end{array}$ & $\begin{array}{r}0.001 \\
>0.001\end{array}$ \\
\hline $\mathrm{RM}$ & 140 & $\begin{array}{l}0.398 \\
0.589\end{array}$ & $\begin{array}{l}>0.001 \\
>0.001\end{array}$ & 50 & $\begin{array}{l}0.415 \\
0.365\end{array}$ & $\begin{array}{l}0.003 \\
0.009 \\
\end{array}$ \\
\hline SF & 140 & $\begin{array}{l}\mathbf{0 . 1 9 5} \\
0.013\end{array}$ & $\begin{array}{l}0.021 \\
0.878\end{array}$ & 50 & $\begin{array}{l}0.355 \\
0.435\end{array}$ & $\begin{array}{l}0.011 \\
0.002\end{array}$ \\
\hline
\end{tabular}




\section{Figure captions}

Figure 1: Bar plots showing averaged voicing (grey) and voiceless (black) durations within the whole frication interval; Bavarian subjects (BM, CF), Northern German subjects (DM, JF, JM, RM), and subject from Saxonia (SF) from top to bottom. Data are separated by phoneme (/s, z, S = / $/, \mathrm{Z}=/ 3 /$ ) and word position ( $\mathrm{i}=$ word initial, $\mathrm{m}=$ word medial, $\mathrm{f}=$ word final).

Figure 2: Bar plots showing averaged ANT in \% (grey) and COG*9 (black), error bars correspond to standard deviations; subjects BM, CF, DM, JF, JM, RM, SF from top to bottom; data are separated by phoneme (/s, z/) and word position ( $\mathrm{i}=$ word initial, $\mathrm{m}=$ word medial, $\mathrm{f}=$ word final).

Figure 3: Example for frequency of contact plot for DP's realisation of initial /z/ (left) versus /s/; dark lines surround the area where electrodes had no contact at all.

Figure 4: Bar plots showing averaged ANT in \% (grey) and COG*9 (black), error bars correspond to standard deviations; subjects BM, CF, DM, JF, JM, RM, SF from top to bottom; data are separated by phoneme ( $\mathrm{S}=/ \mathrm{S} /, \mathrm{Z}=/ 3 /$ ) and word position (i = word initial, $\mathrm{m}$ = word medial, $\mathrm{f}=$ word final). 


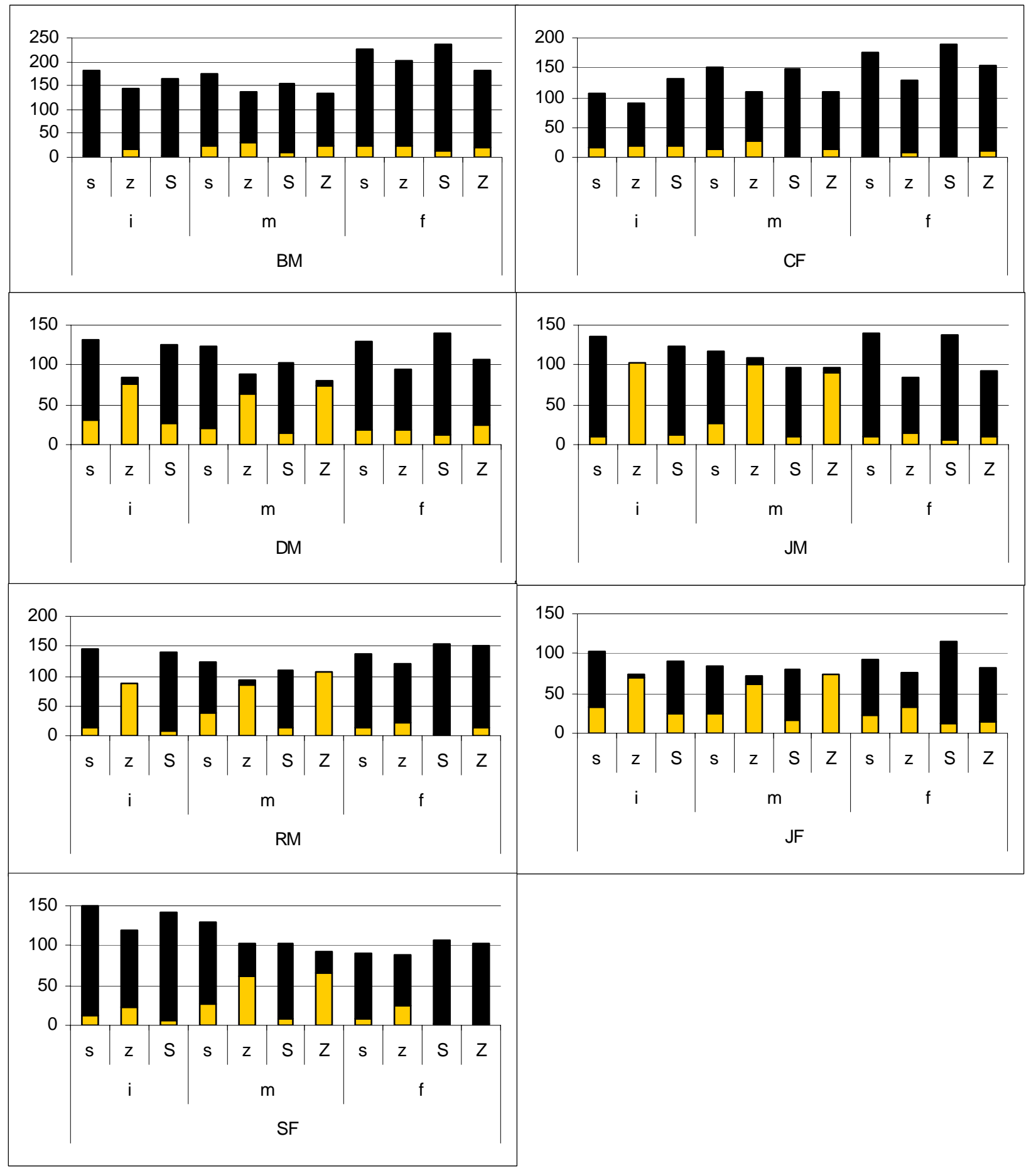

Figure 1 

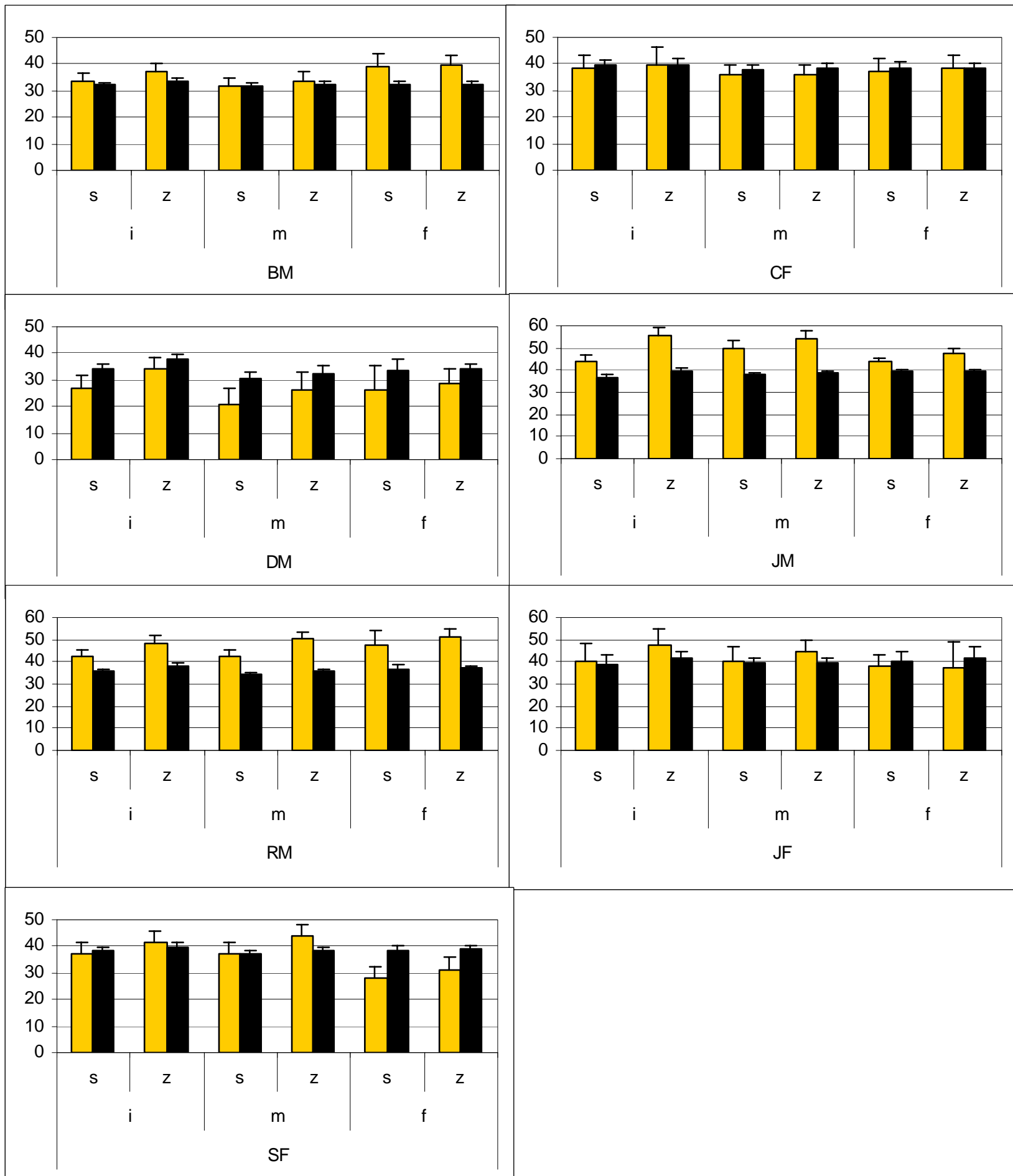

Figure 2 

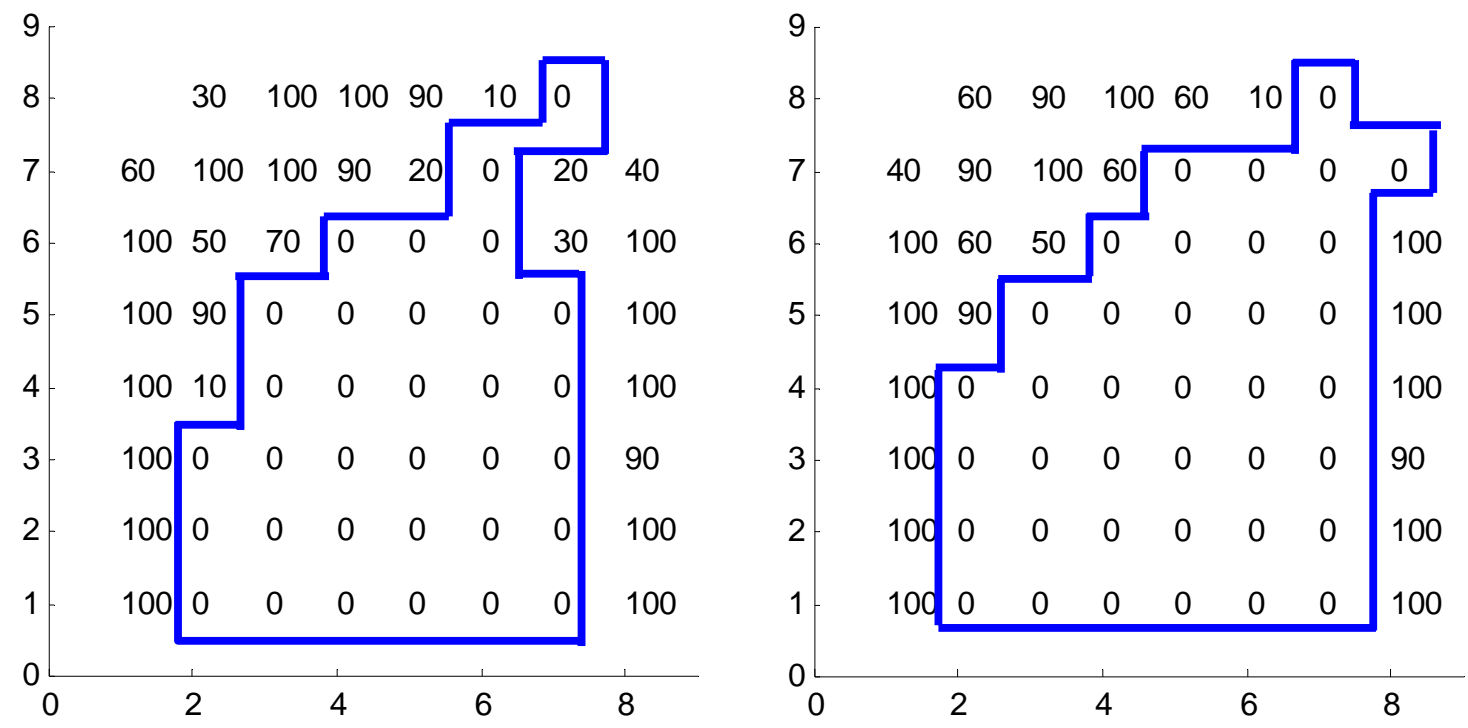

Figure 3 


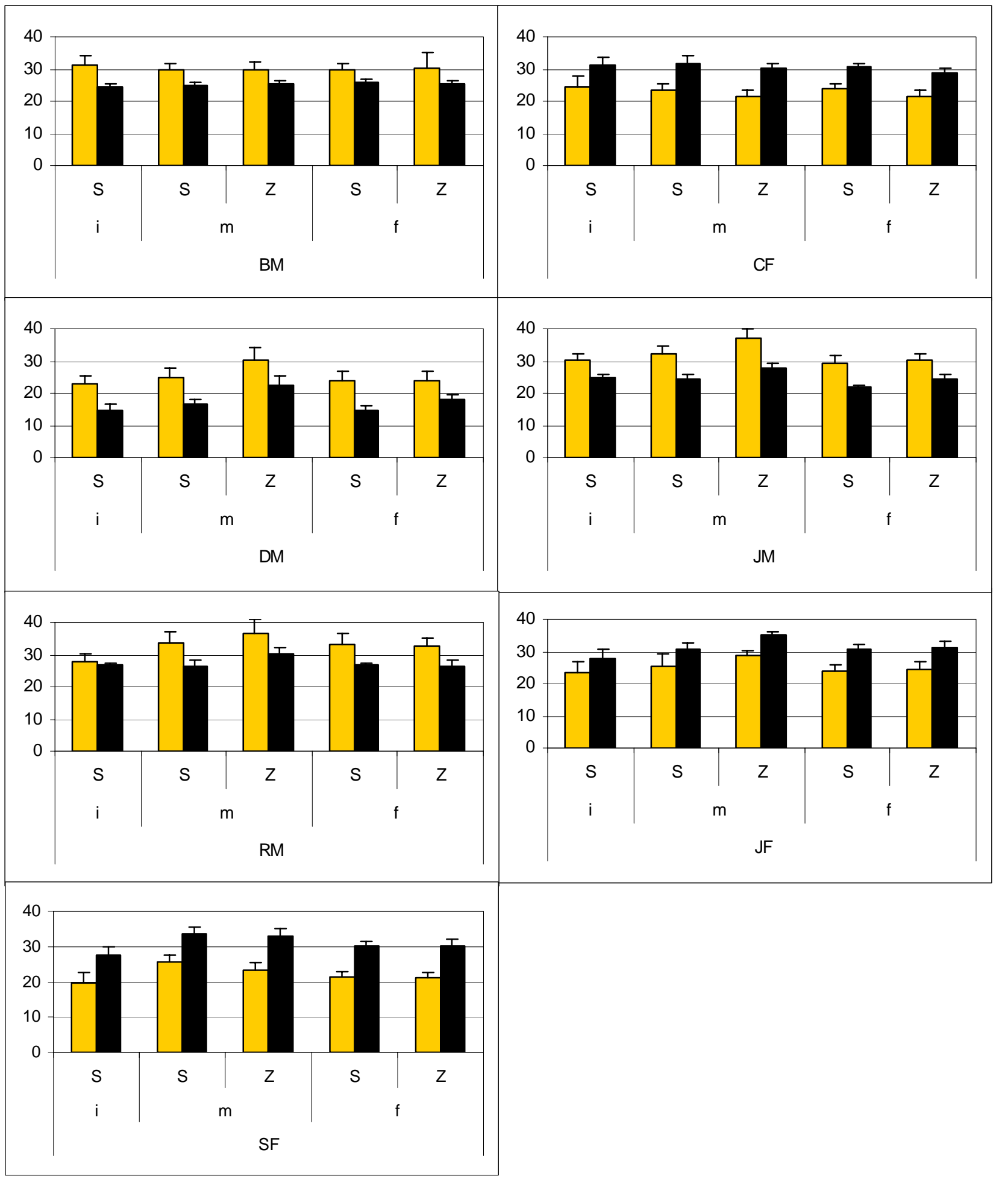

Figure 4 